\title{
Strategic Planning to Advance Equity on Campus: A Case Study at Portland State University
}

Marisa Zapata, Stephen Percy, and Sona Andrews

\begin{abstract}
Propelled by many factors, including a newly appointed Board of Trustees responsible for governance of our university, resource shortages, and enrollment swings, Portland State University embarked on a strategic planning effort in 2014 with the intent of reunifying a divided campus and creating a bold vision for moving forward in the next five years. While committed from the start to goals of diversity and inclusion, the planning process itself generated greater awareness of and commitment to equity - a bolder vision of empowerment that creates a responsibility to understand and mitigate negative, but often unintended consequences of, campus decisions and action-particularly as they impact groups that have experienced institutional racism and injustice. Equity emerged not only as a goal, with intendant initiatives for action, but also as a commitment to conscientious ongoing attention to decision-making that embraces utilization of an equity lens.
\end{abstract}

Key Words: justice; empowerment; equity lens; unity

\section{Introduction}

One would be hard-pressed to find any university that does not have, or is not currently developing, a strategic plan. Such plans help an organization define its vision, mission, values and priorities. A plan provides an organizational North Star and outlines measurable goals. If done well, a strategic plan is a useful tool for not only large-scale change, but also to guide an organization's day-to-day decisions, ensure accountability, and evaluate progress. Often, strategic plans and their execution fall short of expectations. Individuals often feel time and money were spent, but they are skeptical that little will change and it will be business as usual. Portland State University's (PSU) recent strategic planning process and plan implementation is an example of how a well-executed planning process pushed a university to better define its awareness of and commitment to equity as a strategic priority of the institution. This article describes the state of governance; enrollment, budget and campus climate leading into PSU's strategic planning process. That is followed by an explanation of the use of an equity lens. We conclude with the implementation of the equity lens and reflection on the process.

\section{Backdrop for PSU's Strategic Planning Process}

Portland State University had an opportunity in 2014 to create a new strategic plan. The last comprehensive strategic planning process was completed in 2011, culminating in a 2011-2015 Strategic Plan. It was time, based on the traditional five-year strategic planning cycle, to create a new plan. More importantly, PSU had experienced significant changes in governance, enrollment, state support and campus climate since the 2011-2015 plan's inception 
(described in the sections below). These changes made it imperative for the campus to comprehensively review its position, consider its unique value proposition and brand, and create a strategic plan relevant and appropriate to its future.

Participants in various strategic planning sessions, including those organized for varied campus stakeholder groups, were asked questions to get at the branding dimension. This included questions and conversation about what makes PSU unique and for what qualities and achievements does PSU seek to be known for in the local and higher education communities. The vision statement created for the strategic plan captures much of our aspiration: "Portland State University leads the way to an equitable and sustainable future through academic excellence, urban engagement, and expanding opportunity for all.”

\section{Governance}

Prior to 2013, Portland State University was one of seven public universities in the Oregon University System (OUS). In 2013, the legislature passed Senate Bill 80 (Oregon Legislature 2013), establishing independent governing boards for Oregon's Public Universities. PSU's Board was vested by law with the power and authority to govern the University and to exercise all powers and authority of the University as set forth in the laws of the State of Oregon.

The new Board directed PSU President Wim Wiewel, in the fall of 2014, to initiate a campuswide discussion about PSU's strategic directions, resulting in a new strategic plan. The Board's resolution stated (PSU Board of Trustees 2014), "The plan should be completed by the end of the 2014-15 academic year, or early fall 2015 at the latest, and should be a high-level strategic plan rather than a detailed work plan. The plan should build on PSU's historical role and strength and its current vision and mission.” The Board made clear its wishes to be involved in the planning process through representation, regular updates, and consultation.

\section{Enrollment and State Support}

A look into enrollment trends and state support help tell part of the story of what was occurring at PSU over the past decade or half a decade. PSU saw an increase in student enrollment of 20, 026 to 29,818 from 2010 to 2016. This growth in new students was intentional as a result of PSU's urban access mission, but done at a time of great fluctuations in state funding (figure 1). 


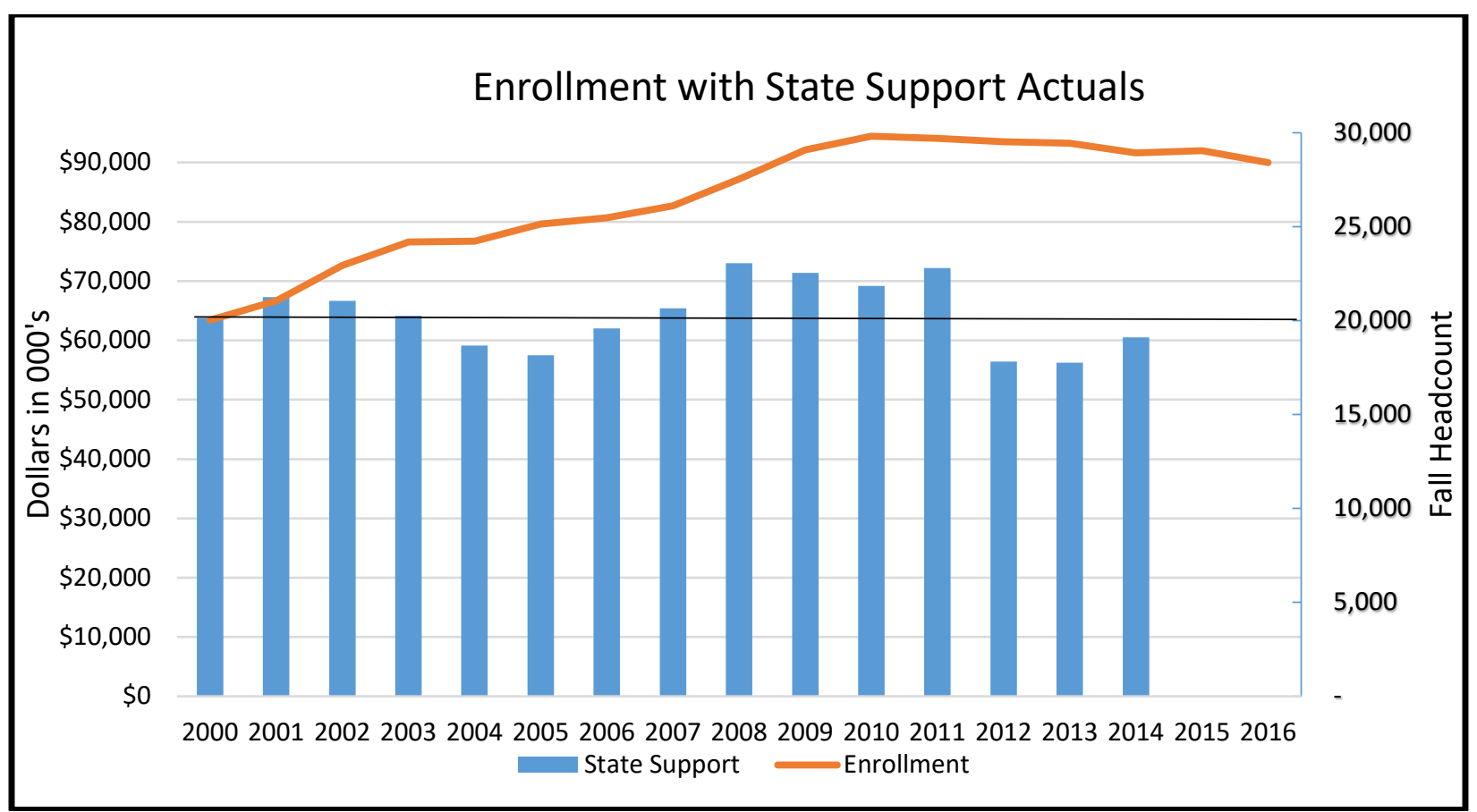

Figure 1.

The lack of predictability in state funding, and the growth and later subsequent flat or declining enrollment, created significant challenges for the university. The university also saw a change in the ethnicity of students in the five years leading up to a new strategic planning effort. This was a purposeful effort by the university as part of our urban serving mission and recognition of the changing demographics in our region. The growth in students who identified with an ethnic minority (figure 2) increased 33\% from 2010 (5,710 students) to 2014 (7,643 students).

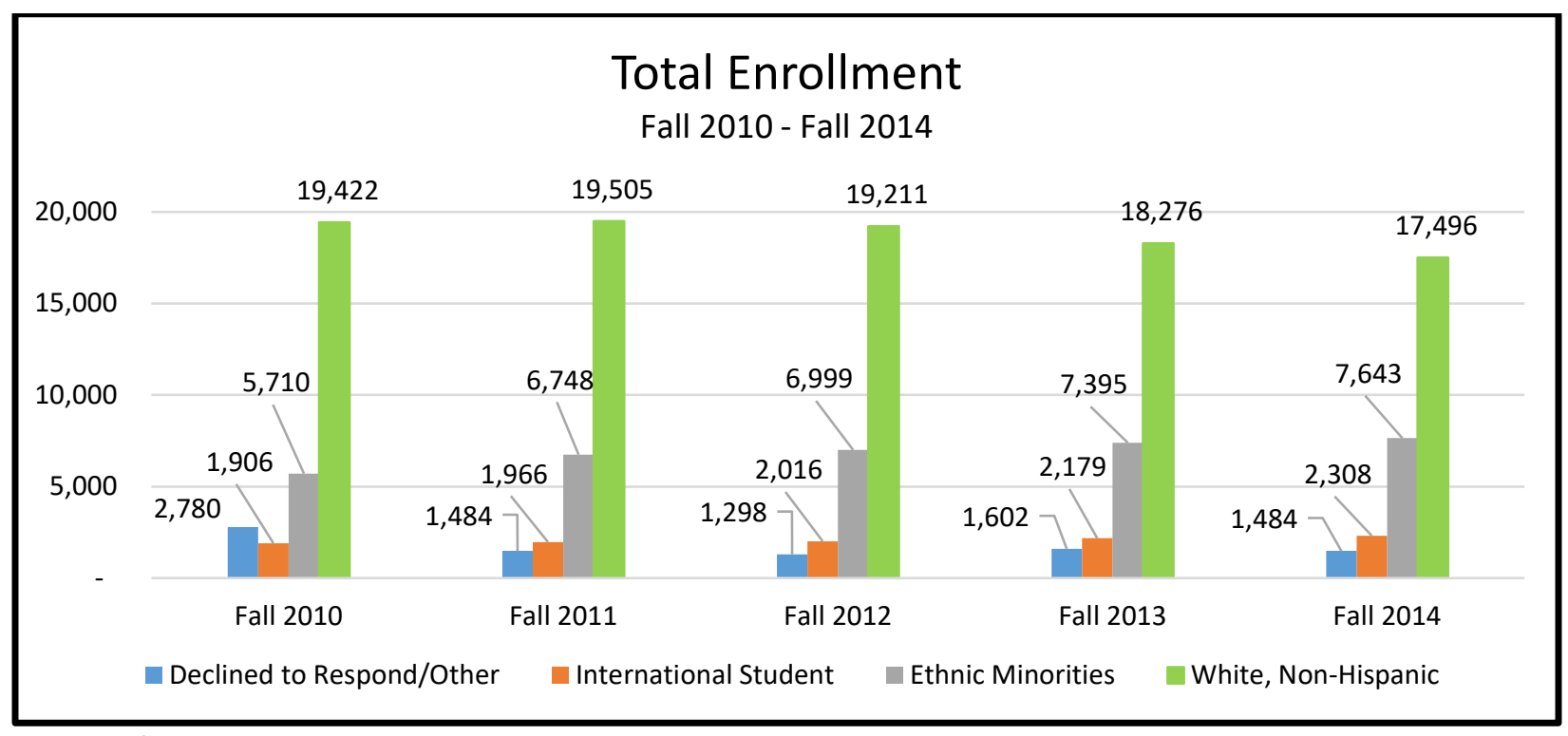

Figure 2. 


\section{Campus Climate}

Morale on the PSU campus was at a low in the winter of 2014. The University had to make budget reductions due to declining enrollment, state funding levels at an all-time low in 2012 and 2013, and increased operational costs. The campus administration and the PSU Association of American Colleges and Universities (AAUP) were in the midst of very protracted collective bargaining negotiations. There were differing opinions about shared governance roles and understanding of the budget. The administration and union came to an impasse during the negotiations and the PSU AAUP membership voted to strike. The contract was settled before a strike occurred, but it signaled a level of campus disharmony between faculty, staff and the administration.

It was not clear what the underlying differences and goals were among faculty, staff, students and administrators. The 2014 strategic planning process was seen as a vehicle to create a collective set of values and vision for the university and improve campus climate. There was significant concern, even skepticism, that a planning effort would unite the university or would tear us more apart. The need to mitigate those concerns led to an intentional planning process from inception through implementation-one aimed at bringing the campus together through an inclusive and authentic process.

\section{One Voice, One Plan}

The Board of Trustees resolution stated, “The plan should be developed with involvement from internal and external constituencies such as the Faculty Senate, Student Senate, represented and unrepresented employee groups, the PSU Foundation and alumni association, and key external stakeholders.” The university administration publicly committed that the process would be defined by open communication, high involvement, transparency, and a drive toward alignment. A large convening of faculty, staff, and student representatives and administrator took place and there was agreement that we needed to improve relations and work together. In spring 2014, 85 people, including faculty, staff, students, administrative leaders, and Trustees convened to take a unifying first step in developing PSU's next strategic plan. The collaborative structure of the day was "an important early precedent for how the plan will be developed in the months ahead.” Participants were provided with an Immersion Toolkit (PSU Toolkit 2015) to access relevant information and questions.

The strategic planning effort was organized through the President's Office with direct involvement throughout the process by President Wiewel, administrators, faculty, staff, students, alumni and members of the Board. Coraggio Group, a Portland-based consulting firm with significant higher education experience, was selected to facilitate the planning process. The university hired a project manager to support the extensive administrative and coordinating efforts of the planning process.

\section{Creating Diversity in Leading Planning Efforts}

A diverse, 30-member Strategic Planning Development Team (SPDT) was created to provide overall guidance to the development of the new strategic plan. Careful attention was given to 
determining the membership of the committee to create as diverse as possible membership, with diversity reflecting stakeholder groups, demographic composition (including race, ethnicity, and gender), and experiences in university life. The Team was led by a dean, and included faculty (tenured, tenure-track, non-tenure track, and adjuncts), staff, unions, graduate and undergraduate students, administrators, a member of the Board of Trustees, and alumni. This group met every two weeks for two hours over several months and took its leadership charge very seriously, overseeing both process and the development of the evolving strategic planning document.

Six-months into the process another set of teams, what we termed "Topic Team," were created. They were given responsibility to create reports on the findings and recommendations around eight key themes that had emerged in a variety of listening and conversation sessions. The eight themes included: Student Learning and Academic Success; Innovative Research, Scholarship \& Creative Activity; Equity, Opportunity and Access; Campus Climate; Faculty Roles \& Structure; Organizational Excellence and Financial Stability; and Global Excellence. Each topic team included members of the SPDT in addition to many other members of the campus community reflecting diverse roles within the university.

Still later in the process during the summer term, a Writing Team was created to craft a preliminary draft of the plan based upon the work, idea generation, and synthesis that took place during the academic year. The team was composed of the SPDT chair, two faculty members, two staff, and three students. The preliminary draft was shared with the strategic planning development team and campus community for comment and revision to in the ensuing fall term. The plan was completed and approved by the Board of Trustees in December 2015.

A key element of the strategic planning process was extensive outreach. Multiple strategies were used to gain both input about elements important to the plan, as well as to emerging goals and actions. These efforts included presentations and consultation with governance groups including the faculty and student senates, listening sessions with other campus groups (e.g., meetings with department chairs, collective bargaining unions), open town hall meetings to which all members of the campus community were invited, and a web-based program to receive input. Perhaps our most innovative, and fun, outreach method was "strategic ice cream," two events created primarily to reach the campus student body. At these events, a large-scale rendering of evolving strategic plan elements was presented. Students were invited to place notations on plan elements and then were given coupons to obtain a free ice cream cone at the adjacent Ben \& Jerry's (a social enterprise preparing youth from disadvantaged backgrounds about employment, leadership, and entrepreneurship). Over 800 students participated in one or both ice cream events.

These outreach activities provided opportunity for thousands of people to participate in the strategic planning process. In total, there were 3,802 official comments recorded during the planning process (870, students, 469 faculty, 438 staff and administrators, 142 alumni and community members, and 1883 who did not identify). This outreach was designed to provide multiple opportunities for people to become involved and specifically sought out opportunities to interact with as many members of the campus community as possible. It covered campus interest in delving deeper into equity, privilege and fairness of outcomes. 
The University spent 14 months to create the new strategic plan. The use of an equity lens was a defining part of the planning process, the plan and its implementation.

\section{Adoption of an Equity Lens in Campus Strategic Planning}

Toward the start of the strategic planning process, with the membership of the Strategic Planning Development Team (SPDT) identified, the planning process was launched. This included meetings with campus constituencies. Early in these conversations, a faculty colleague in the School of Social Work, Dr. Charlotte Goodluck (a colleague who exemplified a life-long dedication to social justice and healing), asked a question which caught the planning team a bit off-guard: "Were we intending to use an equity lens as we embarked on our strategic planning endeavor?” While the School of Social Work was already using such a lens in its own strategic planning, the concept was not widely understood or appreciated by the SPDT or the consultants engaged in the process. After further conversations where participants came to better understand the concept of equity lens, consensus emerged that we should indeed broaden our planning work to explicitly employ an equity lens.

The positive response to Dr. Goodluck's question could have been anticipated. Portland State has a long history of community engagement, consistent with its motto: "Let Knowledge Serve the City.” The lion's share of this engagement focused on advancing life quality, public policy and governance in Portland and Oregon, and much of this work included a social justice dimension. In addition, the concept of responding to inequality was sweeping across the community at the time strategic planning at PSU began. This community attention grew, in large measure, from a report by PSU’s Professor Anne Curry-Stevens, Senior Research Assistant, Amanda CrossHemmer, and the Coalition of Communities of Color which dramatically highlighted substantial disparities between whites and people of color in the county in which the City of Portland is located. This report found that, "Today in Multnomah County, too many people of color face severe social and economic exclusion” (Curry-Stevens, Cross-Hemmer, and Coalition of Communities of Color, 2010: 6).

The propensity to endorse the use of an equity lens in campus strategic planning was also fostered by the recognition that local governments in the area were already at work using an equity lens (for example Multnomah County’s Equity and Empowerment Lens and City of Portland Racial Equity Goals and Strategies). The work of these governments provided insight to the creation and application of an equity lens. Similarly, the region's largest philanthropic foundation, after suspending grants for a year of introspection, reorganized its entire giving program around the concept of equity. The Meyer Memorial Trust's mission was reestablished in 2016 to become: "Grounded in a vision of a flourishing and equitable Oregon, Meyer is committed to investing in change at the systemic level to ease inequities and disparities." See https://mmt.org/. Finally, and importantly, campus community members recognized that Oregon's record in race relations has often not been a positive one. A recent article recognized Portland's progressive reputation, but also noted this reputation ignores the fact that "racism has been entrenched in Oregon, maybe more than any state in the north, for nearly two centuries" (Semuels, 2016). Many faculty at PSU were committed to undoing injustice and expanding the community’s progressive reputation to include equity and positive race relations. 


\section{From Commitment to Equity Lens Development}

Fortunate for the campus, extensive expertise regarding utilization of an equity lens was available both among faculty colleagues as well as leaders in public and nonprofit organizations in the greater Portland region. The first step in moving forward was identifying members of an Equity Lens Team that would guide the creation and application of such a lens as an integral component of the strategic planning process. The team was composed of faculty across the campus who had expertise with equity issues and who themselves represented substantial diversity, along with a representative from Multnomah County government. Multnomah County, in which the City of Portland is located, is a leader in creating and utilizing an equity lens in policy making.

As this new team commenced conversations, a critical question arose: how should we focus the equity lens? On the one hand, this work often targets the realm of populations of people who have been traditionally marginalized in American society and governance. The university has a responsibility to serve, support, and empower faculty, staff, and students from all such marginalized groups. On the other hand, it was recognized that race is a pernicious and longstanding source of marginalization. It was argued that including race together with all other marginalized populations would dilute attention from the persistent impact of race on equity and social justice. After further conversations, it was decided that we would form two parallel and interacting Equity Lens Teams, one focused directly upon race, the other attuned to marginalization of people based upon gender, ability, LGBT, veteran status, and tribal sovereignty. This two-team strategy was intended to ensure focused attention upon race as an equity imperative, but also include other forms of marginalization that have reduced opportunities and bred discrimination.

The next step to implement the equity lens into strategic planning was to create a guide to instruct participants about the intent and practice of using the lens. Our guiding document for using an equity lens in campus strategic planning can be found at:

https://www.pdx.edu/president/sites/www.pdx.edu.president/files/Strategic\%20Planning\%20Equ ity\%20Lens_FINAL\%20-\%20May\%2012.pdf.

This guide borrows heavily from the Multnomah County Equity and Empowerment Lens and from the Protocol for Culturally Responsive Organizations by Ann Curry-Stevens, Marie-Elena Reyes \& the Coalition of Communities of Color. This work in creating such a guide was handled by an 11-member team composed of campus and community representatives. The guide laid out several "guiding principles" for using an equity lens:

1. PSU has a commitment to erase racial disparities in society and advance social justice.

2. At PSU, equity is given the same emphasis as other university priorities.

3. PSU is committed to ensuring that its Strategic Plan reflects the interests of those most affected by our decisions: our students, their future employers, and the service users, customers and/or communities they will ultimately serve. We endeavor to support all students to reach their fullest potential and wellbeing. 
4. PSU is cautious of making decisions on behalf of marginalized communities and aims to directly include these communities and their advocates wherever practical. Decisions to not include these stakeholders need to be justified.

5. PSU aims to create a strategic plan, and the processes that lead up to it, that maximizes the benefits for communities of color and for other marginalized communities.

The guide also provided a list of questions that should be considered during planning and decision. Together, utilization of these questions and their answers represents application of an equity lens. These questions included the following:

People

- Who is affected-positively, negatively, or not at all-by the elements of this part of the strategic plan and what are the specific advantages and/or barriers to each group?

- How have we considered environmental justice in this (initiative/plan element) — that is, how will these initiatives support the rights of all people to live in a healthy environment?

- How have we adequately ensured that our operational processes are inclusive, and that the elements of the process have not created barriers to meaningful participation?

- Which stakeholder groups would we like to have included but were unable to facilitate?

Place

- Based on PSU's social, physical, and cultural location, how does this process compensate for access limitations of various stakeholder groups?

- How have we modified our process to support access by marginalized community stakeholders?

Process

- How does this (initiative/plan element) foster the development of processes that address barriers to inclusion and contribute to the development of community capacity?

- How are our processes supporting the empowerment of communities historically most affected by inequities?

- How are processes ensuring that participants' emotional and physical safety needs are addressed?

- How are processes supporting participants' need to be productive and feel valued?

- How are our processes building ongoing community capacity for involvement with PSU (beyond the strategic planning process) by those communities historically most affected by inequities?

- How are we using this opportunity to contribute to the leadership development of those from marginalized communities?

- What types of biases have influenced the work of the groups and how have these been identified and addressed?

- What improvements to team processes can you support for naming and identifying unaddressed bias?

- What have we learned about effective empowerment practice that we recommend being continued by PSU in other program and initiative development processes?

- What recommendations do we suggest for the future work of PSU? 
Power

- How will this (initiative/plan element) support the empowerment of people from historically marginalized communities?

- What are the specific ways that this (initiative/plan element) is expected to reduce disparities and advance social justice?

The guide concluded with a description of how implementation and documentation should be conducted as well as a set of definitions for key concepts related to equity and social justice.

\section{Organizing Processes to Incorporate an Equity Lens into Planning}

With both a commitment and guide to practice in place, the next step was to infuse use of the equity lens into the overall strategic planning process. This was accomplished in multiple ways.

1. The Strategic Development Planning Team received instruction on the purpose and application of the lens, with the expectation that discussions and decisions would be informed by application of the equity lens as outlined in the guide.

2. The eight Topic Teams were trained in the utilization of the lens and instructed in templates provided to record their recommendations to include equity-based considerations related to each proposed recommendation.

3. One of the eight Topic Teams was organized expressly around equity, opportunity and access. This team embraced the full meaning of the equity lens and focused on strategies that would strengthen the capacity and impact of the university to consistently and persistently pursue equity and social justice.

4. The two Equity Lens Teams — one focused on race and the other on other marginalized groups-reviewed the work of the SPDT and the Topic Teams as work was done to design recommendations for the Strategic Plan. The teams, therefore, represented a second-level equity lens consideration of decisions and recommendations created during the planning process.

It is useful to note that this approach represented both horizontal and vertical application of the equity lens. While one team looked specifically at focused strategies to promote equity and justice (the vertical dimensions), all other teams were expected to consider equity issues in the specific areas they were exploring (the horizontal dimension).

\section{Using the Equity Lens in Practice}

While intentions were good, implementation of the equity lens work was a challenge. We were imperfect, we struggled with sufficiently embedding the equity lens consistently at all stages of the planning process, and mistakes were made. We tried to be flexible, respond to concerns, and modify planning processes and timelines as appropriate.

While faculty and staff were pleased to see the creation of the Equity Lens Teams, the members of the teams expressed frustration at the fact that the Lens was created well into the development of the plan. Nearly all the members of the two teams were from historically marginalized 
communities, and knew well the possibilities of tokenization. Still, the team members also saw the opportunity to integrate equity thinking into the PSU strategic plan for the first time. Concerns were expressed to the Writing Team that in turn responded in detail about what could be changed mid-process and what could not be changed, an important step in process transparency. In particular, the Equity Teams pushed to have the timeline for writing the plan delayed so that the equity work could be better integrated into the planning process. While the time line could not be extended for long, the Writing Team did pause any decisions about specific initiatives until the Equity Lens teams were able to fully organize and review documents. The Project Support Team, in response to the concerns raised by the Equity Teams, laid out a clear process for the Equity Teams' perspectives and participation would be integrated into the writing process including review processes and guarantees of not finalizing the Writing Team work until the Equity Lens teams were able to review all the components of the plan.

Initially, the two Equity Teams met separately; however, the members realized that several people of color came with intersecting identities and were assigned to the team not focused on race. The team members on the team focused on other historically marginalized groups spoke about their commitment to racial equity. In the end, the groups joined to complete their work. While the groups ended up working jointly for the duration of the process, they agreed it was important to begin their work separately and discuss what it meant to keep racism foregrounded.

The timeline and work plan for the strategic plan presented several challenges for the equity lens teams. First, with much work already completed, the team members faced functioning as equity “police," reviewing work for whether it met the teams' expectations for equity considerations. The team members were not enthusiastic about this role, and worked to offer solutions when they pointed out problems. To accomplish this, the Equity Teams reviewed each set of ideas presented by the other Topic Teams. They then raised questions about the equitableness of the proposed actions. Finally, the teams offered other issues to consider within the given topic area based the teams' knowledge areas. These questions and suggestions were then routed to the topic team or the writing team, and from there included or rejected.

From their work, the Equity Lens teams had significant impact on the final plan. Specific plan elements were modified or changed. For instance, in early plan documents, the Equity, Opportunity and Access Topic Team proposed including study abroad as one of their core actions. The Equity Lens teams discussed that study abroad may be an important goal to further student international experience and expose students to diverse set of people and perspectives. However, study abroad in and of itself was not about equity. The Equity Lens teams proposed moving study abroad to an area outside of the section focused on equity. In the final Strategic Plan, study abroad is discussed under Goal 1: Elevating student success.

Reflecting the vertical and horizontal approach to equity discussed earlier, each topic area also includes a separate set of equity considerations. For instance, under Goal 2: Advance excellence in teaching and research, there are four initiative areas. Equity issues are addressed in three of them including proposed actions such as identifying ways to evaluate teaching that do not rely solely on student course evaluations which research has shown disproportionately negatively rate women and faculty of color, and to ensure research areas that received limited funding opportunities are supported - research areas that often include racial foci. Then, the goal includes 
a discussion of general equity concerns that cut across the initiative areas. For instance, the Equity Lens teams proposed: “Consider differentiating PSU in the marketplace by re-branding our scholarly outputs to reflect specific values related to equity, collaboration, and reciprocitythat are community-based and partnership focused” (p. 11).

\section{The New Strategic Plan Addresses Equity}

Directly as a result of the attention to equity in our strategic planning process, the final plan itself embraces equity as an ongoing goal of the institution. Further, it commits the campus to using an equity lens in campus decision-making and planning. The plan speaks to equity in the following ways:

1. Statement of Commitment: "We commit to equity as a foundation of PSU's excellence. We define equity as ensuring everyone has access to opportunities necessary to satisfy essential needs, advance their well-being, and achieve their full potential. Our aim is to address the roots of inequities, including but not limited to racism, homophobia, sexism, ableism, classism, and the intersections of these inequities. We commit to inclusion of historically marginalized communities and those underrepresented in higher education. We commit to ensuring that equity is integral to all elements of this plan-in its design, substance, implementation and the metrics used to measure progress."

2. One of Four Core Values: We promote access, inclusion, and equity as pillars of excellence.

3. Goal 4 of the Plan: Expand Our Commitment to Equity: Objective: Create an environment at PSU that is open, inclusive and committed to diversity, and ensure that all students and faculty embrace culturally-responsive teaching and learning. Three Initiatives of the Goal: (1) Create a more inclusive campus, (2) promote diversity through hiring and retention, and (3) define and measure diversity learning outcomes. Part of this work discusses the development of an equity lens to be used in campus decision-making, and is discussed in more detail elsewhere in this focus issue as well.

4. Equity Lens Considerations: Each of the five goals of the plan include an "Equity Lens" section which identifies some key equity issues potentially associated with implementation of the goal. For example, the following equity lens considerations were identified for the Elevate Student Success Goal (number one in the plan):

a. Recognize that disparities in the retention and graduation rates of underrepresented students necessitate an investment in culturally-responsive advising.

b. Support faculty to understand equity issues to foster better relationships with historically marginalized and underrepresented students.

c. Develop academic experiences, including community-based learning that use universal design, accessibility and appropriate accommodations to ensure an equitable and inclusive learning experience for all students.

These markers in the new strategic plan demonstrate full embrace of equity as a campus priority and a commitment to sustaining attention to and achievement of greater equity in campus life, learning, collegial relationships, and community engagement. 


\section{Lessons Learned, Reflections on Replication}

There is a great deal to be learned from the planning process. After the Equity Lens team concluded its work, several members submitted a short "minority report" that detailed reflections, concerns, and lessons for future work on the PSU campus around equity. Based on the authors' reflections, the Equity Lens team report, and input from other process participants, we offer nine lessons to promote an authentic engagement around equity lenses.

- Bring in equity at the start. While the Equity Lens teams believed that the inclusion of equity at any point was a worthwhile activity, the members saw lost opportunities for better equity integration and capacity building across the campus to do equity work. Integrating equity across topic areas where people have not previously thought about equity takes time. Ideally, integration should also include a learning or training component. In some areas, people may not have thought about inequity before. Those individuals must be introduced to the concept of equity, why it matters, and how to identify inequities. Otherwise, campuses risk creating a team of highly specialized equity "police," and miss the opportunity for all campus members to begin thinking equitably. Incorporating equity early on would also allow participants to develop their own equity lens approach for the consideration of ideas and proposals for the plan.

- Process transparency. Participants in planning processes should be able to easily identify how their input was used in a plan. If it was not incorporated, then participants should understand why their ideas, recommendations, or concerns were not included. Generally, those who often asked to do equity work are people from marginalized backgrounds. Their ideas may often be pushed aside or ignored for other ideas offered by people from majority communities. In addition to issues around marginalization, cross-group learning can only occur if people are able to understand how an idea was interpreted, or why it might be better addressed elsewhere. A commitment to this type of transparency provides several logistical issues - namely how to keep track of suggestions, in this case, across writing teams. We suggest using something simple like a spreadsheet where recommendations are logged and how those recommendations are addressed is tracked.

- Organization and alignment. If recommendations are to be taken seriously within the plan, then the timeline must include space for equity issues to be considered. Careful organization and scheduling to align preparation of findings and inputs from the equity lens teams into discussions and decision making regarding the contents of the strategic plan must occur. All plans end up off schedule at some time; however, many people underestimate the amount of time applying an equity lens can take when utilizing the tool is new when people are unfamiliar with it.

- Involving the "right” people. Questions were raised a number of times during the planning about leadership and participants in process. Efforts were made to be as inclusive and diverse as possible, however, we had to also accept that composition of the university leadership team and the faculty was not as diverse as we would have liked for some of the conversations. By integrating equity thinking earlier into the process, a better 
mix of people might have been included in the process. At the same time, sometimes individuals need to learn how to do equity work in smaller groups. If part of the goal of incorporating equity includes building capacity amongst participants new to equity work, then process conveners must think carefully about when and how to bring people together to with different knowledge bases and experiences with equity work. Different people may be the "right" people at different points of the process and the work.

- Listen and Reflect. The equity lens does not make decisions for you. Rather, it serves as a guide to think about and consider how equity matters in a particular decision. Those people who commit themselves to equity work can offer significant insights into the inequities surrounding a decision. For those less familiar with equity issues in general or the specific equity concerns for a given topic or community, the most important thing to do is to listen carefully to what the lens reveals and reflect on the solutions that are being proposed.

- Difficult Conversations: Opening the door to authentic conversation about equity means that opportunities are made available to people from traditionally marginalized groups to tell their story, report on experiences with discrimination and injustice. These conversations may be difficult in the sense that emotion, anger, and vehement reflections can emerge (Patterson et. al. 2012). Such conversations should be encouraged and supported; those whose background has afforded privilege need to listen to and learn from the experiences of their colleagues who have experienced oppression.

- Explicit Attention to Process: One area where those organizing the strategic planning process fell short was in carefully weaving equity lens consideration and review into the process. As we worked to accommodate many timelines, working groups, and stakeholders, there were times when we did not sufficiently include within the planning process the opportunity of the equity lens teams to review emerging findings and recommendations. While unintentional, these process failures raised substantial concerns among equity team members who became concerned that our intention was not authentic and whether work was truly valued in the process. While we overcame most of these concerns, they could have been avoided if we had been more attuned to including the equity teams consistently and explicitly throughout the process.

- Timelines: Equity work takes time. When that equity work is new to participants, it will take even more time. Plan to go off the time schedule. Part of authentic and good equity work requires working through racial bias, known and unknown. Equity work demands that new data be examined, and difficult conversations be had. Inclusive processes include flexible timelines (Quick and Feldman, 2011). Unfortunately, the PSU strategic plan process timeline was not radically adapted to accommodate the thorough equity work many of us could envision. While the Equity Lens teams, as well as the writing team, worked hard given their time frame, more and better work, especially around building long-term capacity for equity work, could have occurred.

- Bring in Expertise when it is Lacking: The PSU campus was fortunate to have a number of people with experience in developing and using equity lenses. This took on additional 
importance as the consulting firm confirmed that they were not experienced in addressing equity issues. If campus expertise is lacking in applying an equity lens, and if you cannot identity a strategic plan consulting firm with equity experience, we recommend bringing in additional outside support to ensure equity fully infuses your plan.

\section{Implementation}

Once the PSU Strategic Plan 2016-20 was finalized and given approval by the Board of Trustees, the real task began: taking action to implement and assess progress toward strategic goals. Responsibility for organizing implementation of Goal 4 of the Strategic Plan was vested in the 80-member Diversity Action Council (DAC) composed of a diverse array of faculty, staff and administrators. The work of the Council is supported by the campus office of Global Diversity and Inclusion. Taking its responsibility seriously, the DAC has crafted a new diversity action plan for the campus, known as the Diversity, Equity, and Inclusion Plan. The title change was intended to identify our commitment to equity as well as to diversity and inclusion. The plan includes a variety of strategic actions intended to advance the individual goals in the plan.

An important element of implementation will be supporting faculty, staff, and students across the full array of campus units to utilize an equity lens in decision making and planning. Our approach is not to project one standard plan for people to follow. Instead, individual units are encouraged to create their own equity lens, appropriate the realm and impact of decisions made by the unit. To support each units' development of an equity lens tool, the Office of Global Diversity and Inclusion developed a guide to walk them through the process of creating an equity lens (Zapata Forthcoming). The guide, written broadly for institutes of higher education, includes an overview of what an equity lens is, and provides a sample lens and questions to consider for each part of the lens. Two real-life examples from applying an equity lens are included in the report, one from the PSU strategic plan process described in this article, and the other from a Portland local government. The guide provides five hypothetical examples for using the lens drawn from decisions and activities commonly conducted on university and college campuses. As our work at PSU moves forward, we are excited to track how the equity lens is used and informs campus decision-making, another key initiative area from the strategic plan.

\section{Conclusion}

Portland State's experience in using an equity lens as an integral component of strategic planning represents an early adoption of the use of an equity lens approach to advancing inclusion and equitable outcomes. Signs are afoot of awareness in other universities about the value of explicit attention to equity as a fundamental component of strategic planning in higher education. Evidence of this assertion can be found in multiple quarters including Grand Valley State University's Strategic Plan for Inclusion and Equity (n.d.), the Strategic Planning for Equity, Inclusion and Diversity Toolkit published by the University of California-Berkeley (n.d.), and presentations at multiple universities about equity lens applications (for example, a presentation by Equity Alliance of the North Coast (n.d.) entitled "Advancing Equity Through a Racial Lens: Putting Theory into Action at Humboldt State University. 
At Portland State, we have found utilization of an equity lens to substantially advance awareness of and attention to equity in strategic planning. We hope that our experience may be useful to others. Our next step, one to which we are committed but which will require sustained energy, is utilizing an equity lens on an ongoing basis to inform decisions and policy making at our university. We believe commitment to and evaluation of this equity lens work will help us demonstrate what effective work to advance equity looks like, something we hope will inform university practices around the country. 


\section{References}

City of Portland Racial Equity Goals and Strategies. (n.d). Retrieved from https://www.portlandoregon.gov/oehr/article/537589

Curry-Stevens, Ann, Amanda Cross-Hemmer and Coalition of Communities of Color (2010). Communities of Color in Multnomah County: An Unsettling Profile. Portland, OR: Portland State University.

Equity Alliance of the North Coast, (n.d.) “Advancing Equity Through a Racial Lens: Putting Theory into Action at Humboldt State University. Retrieved from:

https://www2.humboldt.edu/events/2016/09/19/6026/).

Grand Valley State University, Strategic Plan for Inclusion and Equity (n.d.) Retrieved from http://www.gvsu.edu/strategicplan-view.htm?entityId=4EBD58CC-B752-DD0F86102A2B73A32989\&entityType=division)

Meyer Memorial Trust. (n.d.). Retrieved from https://mmt.org/

Multnomah County's Equity and Empowerment Lens. (n.d.). Retrieved from https://multco.us/diversity-equity/equity-and-empowerment-lens

PSU Board of Trustees. (2014). Resolution to the President Regarding Strategic Planning. Retrieved from https://www.pdx.edu/sites/www.pdx.edu.board/files/7.\%20Resolution\%20Directing\%20the\%20 President\%20Regarding\%20Strategic\%20Planning\%209-11-14.pdf

PSU Strategical Planning Equity Lens. (May 2012). Retrieved from https://www.pdx.edu/president/sites/www.pdx.edu.president/files/Strategic\%20Planning\%20Equ ity\%20Lens_FINAL\%20-\%20May\%2012.pdf

Portland State University Strategic Plan 2016-2020. (April 2016). Retrieved from https://www.pdx.edu/president/sites/www.pdx.edu.president/files/StrategicPlan2016-4.pdf

PSU Toolkit. (2016). Retrieved from https://www.pdx.edu/president/sites/www.pdx.edu.president/files/PSU.Toolkit.V03.pdf

State of Oregon. (2013) Enrolled. Senate Bill 80. Retrieved from https://olis.leg.state.or.us/liz/2015R1/Downloads/MeasureDocument/SB80/Enrolled

Strategic Plan for Inclusion and Equity. (n.d.). Retrieved from http://www.gvsu.edu/equity/framework-and-strategic-plan-3.htm

Strategic Planning for Equity, Inclusion, and Diversity. (2015). Retrieved from http://diversity.berkeley.edu/sites/default/files/academic-strategic-toolkit-final.pdf 
Quick, Kathryn S. and Martha S. Feldman. 2011. "Distinguishing Participation and Inclusion.” Journal of Planning Education and Research 31(3): 272-90.

Patterson, Kerry, Joseph Grenny, Ron McMillan and Al Switzer. 2012. Crucial Conversations: Tools for Talking When Stakes are High. New York: McCraw Hill.

Semeuls, Alana. (July 2016). "The Racist History of Portland, the Whitest City in America.” The Atlantic. Retrieved from https://www.theatlantic.com/business/archive/2016/07/racisthistoryportland/492035/

University of California-Berkeley (n.d.) the Strategic Planning for Equity, Inclusion and Diversity Toolkit. Retrieved from: http://diversity.berkeley.edu/sites/default/files/academicstrategic-toolkit-final.pdf)

Watson, Jamal Eric. (2016). “An Equity Lens: Portland State University is Emphasizing Diversity as a Shared Responsibility.” Diverse Issues in Higher Education. 22-23.

Zapata, Marisa. (Forthcoming). Making and Using an Equity Lens at Campuses of Higher Education, Portland State University Office of Global Diversity and Inclusion. 


\section{Author Information}

* Marisa Zapata is an Assistant Professor of Land-use Planning at Portland State University. As an educator, scholar, and planner, Dr. Zapata is committed to achieving spatially - based social justice by preparing planners to act in the face of the uncertain and inequitable futures we face. She is especially concerned about equitable planning for uncertain futures in highly diverse communities, and studies how equity lenses can help policy-makers create more just places and institutions.

Marisa A. Zapata, PhD

Portland State University

Toulan School of Urban Studies and Planning

Urban Center, $370 \mathrm{H}$

Email:mazapata@pdx.edu

Telephone: 503-725-8770

Stephen Percy is the Dean of the College of Public Affairs and Professor of Political Science at Portland State University. Previously he served as Dean of the College of Public Affairs at the University of Baltimore and as Professor of Political Science and Director of the Center for Urban Initiatives and Research at the University of Wisconsin-Milwaukee. His interests include university-community engagement, public policy implementation, and disability rights policy.

Stephen Percy

Portland State University

Office of the Dean

Email: spercy@pdx.edu

Telephone: 503-725-4043

Sona Karentz Andrews served as Portland State University's Provost from July 2012 - August 2017. Prior positions include the Vice Chancellor of the Oregon University System, Provost and Vice President for Academic Affairs at Boise State and faculty appointments at the University of Minnesota-Twin Cities, University of Wisconsin-Milwaukee, Boise State University and Portland State University. Her areas of experience include innovation; strategic planning and implementation; leadership development; university budget models and policy development.

Sona K. Andrews

Portland State University

Email: sona.andrews@pdx.edu

* Corresponding Author 